\title{
13th Meeting of International Association of Craniofacial Identification (IACI)
}

\author{
Caroline Wilkinson
}

Published online: 9 January 2009

(C) Humana Press 2009

The 13th Biennial Meeting of the International Association of Craniofacial Identification (IACI) was hosted by the University of Dundee in July 2008, with approximately 100 delegates from over 20 different countries.

The IACI was founded in 1992 in order to bring together those involved in research and practical applications in the field of cranio-facial identification in an international setting.

The title of the congress, 21st Century Challenges to Facial Identification, stressed the importance of current developments both within the field and the world at large. The program was divided into three subject days; Facial Identification of the Dead, Facial Identification of the Living, and Facial Data Acquisition \& Modeling.

The first session discussed technological advances in facial identification of the dead and was opened with a key note presentation by Prof. Dirk Vandermeulen from the Medical Image Computing Centre, Leuven who spoke on the subject of Computer-based Craniofacial Reconstruction. Papers in this session were from subjects as varied as forensic dentistry, the facial reconstruction of historical figures such as Tut-Ankh-Amun and J.S. Bach, and Homicide Detection from China.

The second session discussed soft tissue reconstruction of the dead and was opened with a key note presentation by Ludo Vermeulen, an artist and dentist from Belgium, who discussed whether facial reconstruction is an art or a science. Papers in this session covered nasal shape prediction,

C. Wilkinson $(\square)$

Centre for Anatomy and Human Identification, College of Life

Sciences, University of Dundee, MSI/WTB Complex,

Dow Street, Dundee DD1 5EH, UK

e-mail: C.M.Wilkinson@dundee.ac.uk forensic odontology, comparative studies, and archeological investigations from Norway, Chile, and Poland.

The third session discussed facial data acquisition and was opened with a key note presentation by Prof. Peter Hering, from the University of Dusseldorf, who discussed holographic tomography. Papers in this session included soft tissue data acquisition from Vietnam, Japan, and Belgium, and cranial data from Romania and Australia.

The forth session discussed face modeling and analysis and there were two key note presentations, the first by Prof. Tim Cootes from the University of Manchester who spoke on the subject of statistical models of face appearance, and the second by Prof. Stephen Richmond from the University of Cardiff, who discussed facial characterization and facial growth. Papers in this session covered geometric morphometric analysis, digital face transformation, and 3D modeling using haptic feedback systems.

The fifth session discussed facial recall and recognition of the living and was opened with a key note presentation by Prof. Vicky Bruce, from Newcastle University, who spoke on the subject of the use of face images in forensic investigation. Papers in this session covered facial composite systems, video parade evidence and facial recognition from surface scans.

The final session discussed facial analysis and papers in this session included CCTV identification, plastic surgery, expert evidence in court, age progression systems, and the use of forensic techniques for archeological investigation.

This special edition of the Journal of Forensic Science, Medicine, and Pathology includes all the abstracts and selected papers from this conference. 